\title{
Technological Adjuncts to Enhance Current Psychotherapy Practices: A Review
}

\author{
Bonnie A. Clough ${ }^{\mathrm{a} *}$ \\ Leanne M. Casey ${ }^{\mathrm{a}}$ \\ ${ }^{a}$ Griffith Health Institute, Griffith University, Brisbane, \\ Queensland, Australia
}

*Correspondence should be addressed to Bonnie A. Clough, School of Psychology, Griffith University, Mt Gravatt Campus, Brisbane, QLD 4111, Australia (email: b.clough@griffith.edu.au). Telephone: +61 7 37353348. Fax: +61 737353388. 


\begin{abstract}
Although there are several of reviews of technology in psychology, none to date has focused on technological adjuncts for improving traditional face to face therapy. However, examination of response, adherence, and dropout rates suggests there is considerable scope for improving traditional face to face services. The purpose of this paper was to examine technological adjuncts used to enhance psychotherapy practice. This review focused only on those technologies designed to supplement or enhance traditional therapy methods. Adjuncts designed to reduce direct therapist contact or change the medium of communication were not included. Adjuncts reviewed were mobile phones, personal digital assistants, biofeedback and virtual reality. Limitations in the current literature and directions for future research were identified and discussed. This review provides a comprehensive examination of the way in which adjunctive technologies may be incorporated into face to face therapy.
\end{abstract}

Keywords: cellular phone, mobile phone, virtual reality, biofeedback, personal digital assistants, technology. 
Technological Adjuncts to Enhance Current Psychotherapy Practices: A Review

\section{Psychology and Technology}

\subsection{Technologically Based Interventions}

Psychological interventions can now commonly be accessed by internet websites, phone or video conferencing, email, and even chatrooms (Carlbring \& Andersson, 2006; Goss \& Anthony, 2009). Advantages of these mediums of communication include greater flexibility in treatment timing; objective assessment of treatment compliance; and increased self disclosure and social support (Bull, Gaglio, McKay, \& Glasgow, 2005; Carlbring \& Andersson, 2006; Casey \& Halford, 2010). Furthermore, treatments delivered by these means are more easily disseminated and are more cost effective than traditional psychological interventions (Rothbaum, 2004).

There have been numerous reviews conducted of technologically based interventions (e.g.,Barak, Hen, Boniel-Nissim, \& Shapira, 2008; Carlbring \& Andersson, 2006). A major goal in these reviews has been to examine the way in which technology can be used to replace or duplicate face to face therapy. However, recent research has found approximately $77 \%$ of people would prefer to receive therapy face to face, rather than by electronic means (Klein \& Cook, 2010). As such, there is a need to examine ways in which face to face therapy may be enhanced.

The present review is the first to focus on how technological adjuncts may be able to enhance traditional therapist administered treatments. Some therapists hold negative attitudes toward the implementation of technology in practice. Studies have identified clinician barriers such as a lack of knowledge, being sceptical of the value of technology, as well as cost, time investment and role adjustment (Ager, 1991). 
Understanding the way in which technology can be incorporated into existing psychotherapy will be useful to help bridge some of these gaps.

\subsection{Traditional Interventions}

Traditional psychological treatment methods are far from perfect. Patient dropout, poor engagement, and homework compliance are issues that still plague modern therapy (Addis \& Jacobson, 2000; Burns \& Nolenhoeksema, 1991;

Detweiler-Bedell \& Whisman, 2005; Kluger \& Karras, 1983). These factors often reduce the success and effectiveness of treatment. Even when a treatment course is considered to be successful, patients are usually not symptom free at the end of therapy (Robinson et al., 2006; Taylor, Walters, Vittengl, Krebaum, \& Jarrett, 2010), and relapse rates remain high (Boschen, Neumann, \& Waters, 2009; Halmi et al., 2002). Despite the perceived success of many current psychotherapy approaches, there is still a need for improvement.

\subsection{The Current Review}

The studies included in this review were selected on the basis that they were aimed at incorporating technology to enhance existing therapy practises in the field of clinical psychology. That is, the aim was to improve therapist administered treatment rather than reducing therapist time with the client or changing the medium of therapist communication (e.g., webcam or email). As such, a focus of the present paper was on improving face to face therapies. For the purposes of this review, face to face therapies were deemed to be any mental health intervention, be it group or individual, whereby the clinician has direct, temporal, and physical proximity with a client. The review also focused on applications within clinical psychology, and thus studies from areas such as experimental, neuropsychology, health or organizational psychology were excluded. Although technological adjuncts have been utilized in 
pharmacotherapy (e.g., Kranzler, Abu-Hasaballah, Tennen, Feinn, \& Young, 2004), this area was beyond the scope of the present review.

A comprehensive literature search identified six key areas in which technology has been incorporated into psychotherapy practice: mobile phones, Personal Digital Assitants (PDAs), biofeedback, Virtual Reality (VR), computer games and electronic questionnaires. Of these, computer games and electronic questionnaires were excluded from the review as they were not considered to be unique types of technological adjuncts. Rather, they are technological applications available through a variety of possible adjuncts.

Database searches were conducted for articles published between the years of 1990-2010, using the databases of PsycINFO, Web of Knowledge, and ProQuest Psychology Journals. Search terms were (psychotherapy, psychology, counselling or counseling) paired with key terms for each of the four technological adjuncts; mobile phones (mobile phone, smartphone, short message sevice (SMS), SMS, cell phone or cellular phone), PDAs (personal digital assistant, palmheld computer or PDA), biofeedback (biofeedback) and virtual reality (virtual reality or VR). A search was therefore structured such as, ((psychotherapy or psychology or counseling or counseling) and (“virtual reality” or VR)). Where sufficient data was provided (i.e., means, standard deviations) Cohen's $d$ was calculated as a measure of effect size.

\section{Mobile Phones and PDAs}

\subsection{Overview}

As the PDA may be thought of as a predecessor to the programmable mobile phone (or Smartphone) the two technologies are discussed together.

2.1.1. Advantages. PDAs are small handheld computers used for organization and tracking of daily tasks. PDAs are portable and offer a more natural interface than 
that of traditional desktop computers. Advantages of the PDA include programmability, multimedia input and output capabilities (picture, auditory and video), and options for touch screen, keyboard or stylus operation (Mechling, Gast, \& Seid, 2009). PDAs are also able to handle large quantities of data (Mechling et al., 2009) and entry level devices are becoming increasingly affordable.

However PDAs are quickly becoming replaced by the smartphone. The smartphone has the added functionality of internet access, blue tooth, camera, global positioning system, voice and video calling, and text and picture messaging (Raento, Oulasvirta, \& Eagle, 2009). Other advantages of the smartphone include low initial and maintenance cost, and user friendliness (Boschen \& Casey, 2008). Smartphones may be thought of as portable computers with which the owner has a personal relationship, and which have a greater impact in their social lives (Matthews, Doherty, Sharry, \& Fitzpatrick, 2008; Preziosa, Grassi, Gaggioli, \& Riva, 2009).

2.1.2. Penetration. Smartphone sales are predicted to exceed PDA sales by an 11:1 ratio in 2011 (Computer Industry Almanac, 2006). These figures indicate that whilst the demand for PDA functionality has not declined, consumers are now able to access this functionality through their mobile phone device (Computer Industry Almanac, 2003). This difference in uptake and sales has lead to a large discrepancy in penetration rates between PDAs and mobile phones.

In 2008, mobile phone subscriptions reached over 4 billion worldwide (Banjanovic, 2010). Penetration rates among developing countries are now fast approaching those of developed countries, with wireless infrastructure costing much less to install than fixed line infrastructure (Banjanovic, 2010). In contrast, the PDA has low penetration, estimated at just 7\% in 2008 (Jupiter Research, 2004). Due to this 
low penetration, studies involving PDAs typically require researcher provision of the device for the duration of research, adding to the overall cost of studies.

\subsection{Mobile Phones and PDAs in Psychotherapy.}

Seven studies with mobile phones and four studies with PDAs were identified as using technological adjuncts to enhance existing psychotherapy processes. A summary of the studies is displayed in Table 1. Only four studies contained sufficient information to calculate effect sizes.

\subsection{Mobile Phones and PDAs for Assessment}

Mobile phones and PDAs have both been used in clinical studies for ecological momentary assessment (EMA). EMA is a noninvasive method for collecting real-time data from participants concerning their mood, behaviour, motivation and social activity, during their daily lives (Axelson et al., 2003). EMA traditionally has been conducted using pencil and paper questionnaires, sometimes with participants being prompted by pager for their completion (Larson, Richards, Raffaelli, Ham, \& Jewell, 1990). Studies reviewed in this field have shown medium to strong effect sizes in data collection and ease of use, when compared with traditional EMA methods.

2.3.1. Mobile phones for EMA. Axelson et al. (2003) and Matthews et al. (2008) both examined the feasibility of using mobile phones to collect EMA data in adolescent populations. Whereas Axelson et al. (2003) required participants to answer their mobile phone for brief interviews with a researcher, Matthews et al. (2008) required participants to make one daily mood entry into a programmed mobile phone application that was then compared to a paper and pencil (PP) condition.

Both studies concluded that it was feasible to use mobile phones to collect EMA data, and reported high acceptance among participants. Although the Axelson et 
al. (2003) sample size was too small to conduct statistical analysis on the EMA data, participant attrition was low and only $10 \%$ of calls were missed by participants, indicating high engagement in the task. Matthews el al. (2008) found compliance to be significantly higher in the mobile phone (MP) EMA group than in the PP EMA group, with fewer missed daily entries. Clients also found the mobile phones easier to use. Additionally, this effect may have been underestimated as the study contained no way of objectively assessing compliance in the PP condition where participants may have completed entries retrospectively.

Both the Matthews et al. (2008) and Axelson et al. studies (2003) demonstrate that mobile phones can be used to improve current methods of EMA. A third study conducted by Collins et al. (2003) also demonstrated equivalence between MP and PP monitoring methods among 20 social drinkers.

Mobile phones are likely to become increasingly popular in the collection of clinical data (Boschen \& Casey, 2008). Mobile phones give clinicians direct access to clients, at times and locations that would otherwise not be possible by traditional methods. For many people, mobile phones provide a direct link to their social and support networks. As such many clients maintain a personal relationship with these devices (Matthews et al., 2008), which may result in increased client engagement and adherence with tasks delivered by this method. However, possibly the strongest advantage of the mobile phone is that clients carry the devices on their person throughout the day. It reduces possibility of clients forgetting monitoring charts, or feeling embarrassed about completing tasks in public.

2.3.2. PDAs for EMA. PDAs have also been used for EMA, in the collection of data from patients with schizophrenia (Kimhy et al., 2006). Devices were used to track momentary psychotic symptoms, as well as moods and thoughts. Participants 
were 10 healthy control subjects and 10 hospitalized patients with schizophrenia. Each PDA beeped randomly 10 times a day. Upon hearing the PDA alarm each participant was required to complete a brief survey on the device.

Participants with schizophrenia reported significantly higher ratings of hallucinations, disordered thinking patterns, and depressed mood, with strong effect sizes found (Kimhy et al., 2006). Participants found the devices acceptable to use and reported that they caused minimal disruption to daily activities. However a system crash did result in some loss of data. Furthermore, results are limited in that the data collection period was only one day. High response rates and positive acceptability of the devices may be associated with the technology being a novelty for the participants. Further research would be needed to investigate whether these results remain stable over longer data collection periods. However, this study provides evidence that PDAs may be a useful technological adjunct in collecting data from clinical populations. This use may be particularly relevant in working with clinical populations who may experience difficulties in completing self report measures.

\subsection{Mobile Phones and PDAs for Intervention}

2.4.1. Mobile phones as safety signals. Flynn et al. (1992) reported two case studies in which mobile phones were installed into the cars of two patients receiving treatment for driving phobia. Participants were allowed to call the therapist or other support person whilst in the car by themselves during therapy. Use of the phone was phased out over six weeks. Importantly, the phone was used as an adjunct to the desensitization therapy, and participants still undertook their regular sessions with the psychotherapist.

One patient was able to overcome their fear of driving, however the second patient became dependent on the phone, and repeatedly relapsed upon its removal. 
Therefore, whilst mobile phones can be used effectively during desensitization therapy, it is important that patients do not become dependent on them. However, the use of such a safety device may be particularly useful in the early stages of treatment to gradually build exposure to stimulus (Rachman, Radomsky, \& Shafran, 2008).

2.4.2. Mobile phones for relaxation. A recent study conducted by Grassi et al. (2007) examined use of mobile phones in delivering relaxation exercises. The software program was based on the principles of progressive muscular relaxation and autogenic training. It contained audio and video components to facilitate imagination of calm environments. Participants were randomly assigned to four experimental conditions; combined audio and video delivery, audio only, video only, and control. Participants in the combined audio and visual group experienced significant reductions in anxiety as well as improvements in self efficacy, with medium to strong effect sizes found. No differences were found among other groups. As this study was conducted on healthy control participants, future research should examine whether this method would be appropriate for use among patients with anxiety or depressive disorders.

2.4.3. Mobile phones in psychological aftercare. Two recent studies have focused on the use of SMS text messaging in the aftercare of bulimic patients (Bauer, Percevic, Okon, Meermann, \& Kordy, 2003; Robinson et al., 2006). The SMS-based aftercare intervention was first offered to 30 patients suffering from bulimia nervosa (BN) in a German hospital (Bauer et al., 2003). The program lasted six months following inpatient treatment, and aimed to reduce the risk of relapse.

Participants were sent messages once weekly in a standard format relating to their bulimic symptoms. Participants were required to reply to these messages, and were also able to send additional free messages to the researchers throughout the 
week. The researchers replied with one message per week offering support and advice. These SMS responses were a mixture of pre-programmed and individually tailored components.

Although aggregate data were not available for the initial pilot study, case information was reported from two patients. Results indicated that the SMS aftercare intervention was an appropriate bridge between inpatient treatment and outpatient daily life. The SMS program helped support patients following psychological treatment, and to help them maintain and consolidate the gains achieved in treatment. Following success of the program in Germany (Bauer et al., 2003), an English version of the intervention was piloted on $21 \mathrm{BN}$ patients in the United Kingdom (Robinson et al., 2006). The program however, was designed to begin on completion of outpatient BN therapy rather than inpatient. Although similar software and methodology were used, the UK pilot reported low usage and high attrition rates, with small effect sizes found. Less than half of participants completed the study. The majority viewed the lack of personal contact negatively and would not recommend the program to others.

Key differences between the two studies are that the German participants were given an introduction to the program during treatment, whilst the UK participants were not. Furthermore, unlike the German study, participants in the UK pilot were not selected based on symptom severity which may have led to a sample with more severe symptoms. The authors (Robinson et al., 2006) noted that as the SMS program was a minimal aftercare intervention, it may not have been appropriate for the more severe cases.

The problems in the Robinson et al. (2006) study demonstrate that use of technology in psychotherapy must be well planned and implemented in order to be 
effective. It is important that clinicians do not "add on" technological adjuncts simply because they are available. Rather, these adjuncts must adhere to the goals and aims of the therapy process, and match the specific characteristics of the client and environment for which they are to be implemented.

2.4.4. PDAs to increase independence. Three studies have examined the use of PDAs as a technological adjunct to increase the independence of patients with pervasive developmental disorders (Ferguson, Myles, \& Hagiwara, 2005; Mechling et al., 2009; Myles, Ferguson, \& Hagiwara, 2007). Two studies utilized single case designs involving adolescents diagnosed with Asperger’s Syndrome (AS) (Ferguson et al., 2005; Myles et al., 2007), while the third integrated PDAs into the treatment of adolescents with mild to moderate autism.

Both Ferguson et al. (2005) and Myles et al. (2007) introduced PDAs to decrease reliance on adults at home and at school. Although adolescents with AS typically have average to above average intelligence, many suffer from deficits in organisation and problem solving skills which hinder completion of daily tasks (Attwood, 2004). Ferguson et al. (2005) used PDAs to facilitate completion of tasks, with programmed PDA alarms that sounded audibly and flashed visually. Myles et al. (2007) used the PDA to assist in recording of homework utilizing an electronic planner with specified fields.

Both studies were conducted using multiple baseline designs, and both showed positive treatment effects during intervention phases. During baseline phases in the Ferguson et al. (2005) study, the participant completed 63\% of his school tasks and $0 \%$ of his morning tasks independently. However, during intervention phases these figures rose to $87 \%$ for school tasks and $47 \%$ for morning tasks. Homework recording was found to increase by $29 \%$ during the intervention phases of the Myles et al. 
(2007) study. Unfortunately neither study contained any formal statistical analyses, and results are limited in generalizability by the single case designs. However, results do indicate that the PDA prompts facilitated some increased level of independent organisation in the participants.

Mechling et al. (2009) used PDAs to increase independence when conducting multistep cooking tasks among autistic students. PDAs provided audio and visual prompts at each step of the tasks, with the aim of promoting internal prompting and decreasing external prompting. The level of prompts was able to be controlled by the participants, so that they could be faded to a less intrusive level or removed completely over time.

A multiple baseline approach was utilized. Students performed a greater percentage of cooking steps correctly during the PDA phases than during the non PDA phases. Over time participant performance during the non PDA phases also increased in accuracy, indicating that PDA prompts were facilitating independent self prompting even when the device was removed. However, it is unclear how substantial these gains were as no statistical analyses were performed, and the individual treatment effects of each type of prompt is unknown, as they were not tested separately. Despite these limitations, the Mechling et al. (2009) study provides further evidence that PDAs may be a promising technological adjunct to promote independence among adolescents with pervasive developmental disorders.

\subsection{Current Research, Limitations and Future Directions}

Mobile phones and PDAs have the potential to enhance psychotherapy in a variety of ways. Studies thus far have demonstrated the feasibility of using these devices in clinical assessment and intervention. EMA processes may prove to be more accurate than traditional pencil and paper monitoring, and may also increase 
compliance to the task. This method may save both patient and clinician time in entering and collating data. Devices may also be useful in the treatment and aftercare of patients, by acting as a bridge between the therapist and client, and for increasing the independence of patients with developmental disorders. Furthermore, the devices are unobtrusive and are often already carried and used by the client on a daily basis.

A variety of mechanisms has been suggested as to how and why such technology may be effective in clinical psychology. It has been suggested that the increased and more personal style of communication associated with these technologies may facilitate growth of the therapeutic alliance (Liebert, Archer, Munson, \& York, 2006; Murdoch \& Connor-Greene, 2000). As such, these technologies may increase self disclosure and trust between therapist and client. This type of communication and interaction is often more familiar to clients than various other methods used in psychotherapy. Clients have often already had exposure with communicating via electronic mediums, and may even have had exposure with electronic data collection such as online surveys, forms, or quizzes. Clients may deem these mediums of communication to be more familiar, comfortable, and safer than by paper and pencil (Liebert et al., 2006). Therapists will also need to be vigilant that appropriate therapist and client boundaries are maintained with the use of such devices (Coyle, Doherty, Matthews, \& Sharry, 2007).

Presentation of therapeutic material in formats closely resembling that of the real world may also help clients better translate therapeutic principles to real world situations (Favelle, 1994). Translation of learned principles beyond the therapist's office is particularly important for all types of psychotherapy, and is the rationale behind the effectiveness of homework tasks (Freeman \& Rosenfield, 2002). Presenting therapeutic information on devices that are personally and socially relevant 
to the client may aide with integration of these principles into the client's everyday life. Such integration may be particularly important for the maintenance of treatment gains, particularly after treatment has ceased.

Electronic devices may also allow for increased client interaction and enjoyment with therapeutic tasks (Coyle, Matthews, Sharry, Nisbet, \& Doherty, 2005). Interactive games and activities may increase positive affect and attitude whilst engaging in such tasks, in turn leading to higher engagement and more positive attitudes toward treatment plans (Brezinka, 2008). These are all factors which may explain why such technological adjuncts may be effective in enhancing current face to face psychotherapy practices.

However, studies thus far have also demonstrated some of the potential dangers of this technology, such as client dependence and security of data management. Furthermore, like any new component to the therapy process, the introduction of a mobile phone adjunct cannot be done ad hoc. Rather, it must be carefully planned to fit the client's and therapist's expectations, and the aims of the therapeutic program.

Low penetration rates of PDAs are also a significant limitation. Despite the promising results of PDA studies, many clinicians may feel a reluctance to invest in this technology due to the associated costs of providing clients with the devices. Future research may benefit from assessing whether similar results can be achieved when substituting smartphones for PDAs. Researchers have also noted technical difficulties associated with PDA integration, such as PDA crashes, participants forgetting identification codes and passwords, and differing software systems between the devices and linked desktop computers (Yon, Johnson, Harvey-Berino, Gold, \& 
Howard, 2007; Zeman, Johnson, Arfken, Smith, \& Opoku, 2006), many of which may be overcome through using smartphones for similar functions.

Research in this area is still at a very early stage. Future research could examine mobile phones for reminding patients of appointment times, and homework compliance may be able to be increased by transferring tasks to an electronic format. Homework adherence has been identified as a critical factor affecting the success of many forms of therapy (Gonzalez, Schmitz, \& DeLaune, 2006). Despite the increase in technological adjuncts within psychology, many homework assignments are still delivered by pen and paper.

Clients are often required to complete thought and mood charts in paper diaries, and records of relaxation exercises are also still recorded manually. Many of these homework tasks could be converted to an electronic format that the client could complete via PDA or Smartphone. For example, patients undergoing treatment for anxiety disorders may be able to receive reminders on their mobile phones to complete relaxation tasks, or other such therapy activities throughout the day. A programmed application would also be able to guide them through the task, and electronically stamp the time, date and length of the activity. Mobile phones in particular are an adjunct that shows great potential for use in clinical psychology.

\section{Biofeedback}

\subsection{Overview}

Biofeedback is a method of increasing physiological awareness, and helping individuals learn to manipulate various bodily processes such as heart rate, blood pressure, breathing, brain waves, muscle tension, skin temperature and conductance (Ratanasiripong, Sverduk, Hayashino, \& Prince, 2010). The selected physiological 
activity is detected, measured, and transformed into an easily comprehensible format, and displayed back to the individual as they learn to regulate these responses (Coben, Linden, \& Myers, 2010). Biofeedback was of interest to health care researchers in the 1970s, but has only recently become popular in psychology.

Methods of biofeedback have previously often required expensive equipment and specialised training in data collection, interpretation, and maintenance of devices. However recent advances in technology have allowed biofeedback to become an affordable and readily available option for practising clinicians (Ratanasiripong et al., 2010) that may be particularly useful in the treatment of anxiety and mood disorders (Reiner, 2008). Indeed, with the increasing interest in use of mindfulness based therapies, biofeedback may be a useful tool for clinicians to consider. Research has found mindfulness to be associated with specific types of memory and attention processes (Raffone, Tagini, \& Srinivasan, 2010). Specifically mindfulness meditations have been associated with increases in alpha and theta brainwaves, and enhancement of cerebral areas related to attention (Chiesa \& Serretti, 2010). Biofeedback may be useful for training clients in the skills of mindfulness therapy, by allowing them to view changes and observe progress.

Several different instruments can be used to provide biofeedback. An electroencephalograph (EEG) measures brainwaves by means of electrical currents that pass through an individual's scalp (Coben et al., 2010). Using behavioural conditioning individuals can therefore be rewarded and trained to produce certain types of brainwaves. For example Lubar and colleagues rewarded participants with Attention Deficit/Hyperactivity Disorder (ADHD) for increasing theta brainwaves (Lubar, Swartwood, Swartwood, \& Odonnell, 1995). These increases in theta 
brainwaves were associated with improvements in ADHD symptomology, which were maintained for up to 5-10 years following treatment (Lubar et al., 1995).

Electromyography (EMG) has also been used to provide feedback on the physiological properties of muscles (Biondi \& Portuesi, 1994). This approach has been used for relaxation training, and in the treatment of tension type headaches and mood disorders (Biondi \& Portuesi, 1994). Other common biofeedback instruments measure heart rate, blood pressure and breathing.

\subsection{Biofeedback in Psychotherapy}

To date, biofeedback has been used predominantly as a stand alone treatment rather than in combination with traditional psychotherapy. Although there are many published studies examining the efficacy of biofeedback, very few have used it as a technique to enhance current psychotherapy practices. Five studies were identified as using biofeedback as an adjunct to the traditional therapeutic process, and are summarised in Table 2 below. One study contained sufficient information to calculate effect size.

3.2.1. Biofeedback and anxiety. Two studies examined biofeedback as an adjunct to the treatment of patients with anxiety disorders (Ratanasiripong et al., 2010; Reiner, 2008). Both studies used portable biofeedback devices to monitor participants' heart rates, and help teach relaxation and breathing techniques. Training was done in conjunction with cognitive behavioural therapy (CBT) (Reiner, 2008) or counselling (Ratanasiripong et al., 2010).

Ratanasiripong et al. (2010) introduced a biofeedback component to the counseling service provided to students at an American college. Portable biofeedback devices that monitored variability of heart rate were used. Participants were 
introduced to these devices during a regular counselling session, and took them home for practice.

In the first semester following the introduction of the biofeedback component, researchers reported near 100\% compliance with homework tasks and students reportedly enjoyed using the devices. However, data were not collected on any stress or anxiety related outcome measures, nor was there a control group or baseline for comparison.

Reiner (2008) also provided participants with a portable biofeedback device to help manage physiological symptoms of anxiety. Participants were introduced to the device during therapy, and were required to engage in at least 20 minutes of biofeedback training each day for three weeks. This training focused on helping participants control their breathing and heart beat during inhale-exhale cycles. Following the intervention, participants reported significant reductions in anxiety and anger, as well as benefits associated with sleep variables.

While these results are promising, the study lacked a control group. It is therefore not known whether the reported benefits are due to the addition of the biofeedback component, or the result of normal psychotherapy. Furthermore, as the therapist was also the experimenter it is unclear whether this may have created bias in the results. Some participants also reported side effects such as dizziness and fatigue.

3.2.2. Biofeedback and Somatic Disorders. Two studies have examined combined psychotherapy and biofeedback in the treatment of psychogenic cough (Riegel et al., 1995) and anismus (Leroi et al., 1996).

Psychogenic cough is a persistent and disruptive cough that can be debilitating to work and social relationships, and for which there is no radiologic or laboratory signs of abnormality (Riegel et al., 1995). Riegel et al. (1995) combined regular 
psychotherapy sessions with the use of biofeedback with EMG. The patient's weekly therapy sessions focused on stress management, counselling and activity scheduling. The weekly biofeedback sessions involved EMG assisted breathing exercises, muscle relaxation and stretching.

After two weeks of the combined therapy program the patient reported coughing less, sleeping better, and had cut down on antitussive medication. These improvements were maintained at six month follow up. As no statistical analyses were performed and the study is limited by the single case design, it is uncertain whether results can be generalised to wider populations. Furthermore, due to lack of a control condition biofeedback treatment effects cannot be separated from normal psychotherapy effects.

Anismus involves the extreme contraction of the external anal sphincter, and can cause symptoms of irritable bowel disease (Leroi, Berkelmans, Denis, Hemond, \& Devroede, 1995). These symptoms persist despite physical, radiological, and colonic examinations being normal (Leroi et al., 1996). Anismus is frequently related to past sexual abuse (Leroi et al., 1995).

Leroi et al. (1996) examined the use of combined biofeedback and psychotherapy in the treatment of sexually abused women suffering from anismus. Participants were given the option of biofeedback, group therapy, individual therapy, or any combination of the treatments. Biofeedback training involved the use of a rectoanal manometry probe which recorded pressure in the upper part of the anal canal. The aim of the biofeedback training was to recover a normal command of the anal function. Group and individual psychotherapy focused on modifying maladaptive behaviour, finding solutions to problems, and coping with stress and emotional problems. All participants initially selected biofeedback. Of the 13 participants that 
completed the study, five joined group therapy throughout the course of the study, and three joined individual therapy.

Eight of the 13 participants recovered from their symptoms completely. Of these, only two had undertaken biofeedback without psychotherapy. These results indicate that for most patients, psychotherapy was an important component in the treatment of the somatic disorder. However, as no statistical analyses were performed on the data, the size of the treatment effect is unclear. Furthermore, as no participants elected to undergo psychotherapy only, the individual treatment effects of the biofeedback adjunct cannot be identified. However, the study does demonstrate that biofeedback could be a useful bridge to psychotherapeutic treatment, particularly for women not yet ready to undertake psychotherapy. Biofeedback may be a useful adjunct to enhance current psychotherapy treatment for somatic disorders.

3.2.3. Biofeedback and insomnia. McLay and Spira (2009) combined traditional psychotherapy with biofeedback in the treatment of a military patient suffering from insomnia. The patient was serving in a combat zone at the time, and presented with anxiety, depressed mood and insomnia. After six sessions of cognitive behavioural therapy anxiety, depression and self esteem were improved, however insomnia remained a problem.

A handheld device which measured heart rate variability was introduced to the therapy process. The patient was trained in specific breathing and relaxation techniques. The patient reported improved sleep after one week of using the device, and these improvements continued until the end of the six week treatment program. At one year follow up the patient had returned home from deployment and had been diagnosed with post traumatic stress disorder (PTSD) and was still undergoing 
psychotherapy. The patient did however report that he was sleeping well, indicating that the techniques learnt through biofeedback may have had long term effects.

The study is however limited by the single case design, and the fact that no statistical analyses were performed on the data. Regardless of this, the case report does demonstrate that biofeedback was beneficial in improving sleep patterns for this particular patient, particularly when traditional psychotherapy had not been effective.

\subsection{Current Research, Limitations, and Future Directions}

Although there are numerous studies examining biofeedback as a treatment option for many medical and psychological complaints, very little research has examined biofeedback in combination with psychotherapy. Available research suggests that biofeedback could be a valuable adjunct to psychotherapy for the treatment of anxiety, somatic, and sleep related complaints.

Biofeedback may be particularly useful in helping clients understand the physiological responses related to conditions such as anxiety, and how to manage these responses (Chandler, Bodenhamer-Davis, Holden, Evenson, \& Bratton, 2001). Biofeedback also allows clients to visualize and observe improvements in these physiological responses, across the course of treatment (Elton, 1993). Increased awareness and insight is one mechanism by which biofeedback may be an effective technological adjunct in psychotherapy.

Handheld biofeedback devices are small and portable, and allow patients to practise in a variety of environments. Electronic data collection allows for objective assessment of homework compliance, and as such may result in increased client compliance (Ratanasiripong et al., 2010), another mechanism by which this adjunct may operate. Many of the handheld biofeedback devices are also relatively inexpensive and easy to use, and therapists usually do not require additional training. 
Clinicians must however be aware of possible side effects that may result from the use of the biofeedback devices, such as fatigue and dizziness.

Other forms of biofeedback such as EEG and EMG have also shown promising results in the treatment of psychological disorders (e.g., Coben et al., 2010). However, there is no research examining how these approaches can be combined with psychotherapy rather than as an alternative. Even with additional research many therapists may still be reluctant to incorporate such forms of biofeedback into practice. The equipment needed to conduct EEGs and EMGs can be prohibitively expensive, and the additional training involved for clinicians may also be a deterrent. However, such approaches may still be feasible for psychological clinics attached to larger organizations. As such, research is still required to assess the efficacy of EEG and EMG adjuncts to psychotherapy.

Current research has demonstrated that many forms of biofeedback are both feasible and appropriate in combination with psychotherapy. Biofeedback is an important technological adjunct for research and practice, and is likely to receive a boost from the current popularity of mindfulness therapy. The combination of biofeedback and mindfulness therapy is an avenue which has yet to be explored.

\section{Virtual Reality}

\subsection{Overview}

VR refers to the perceptual experience created by a collection of technological devices that together, construct the illusion of an interactive, three-dimensional world (Riva, 2003). It is the sense of immersion or presence that separates virtual reality from various other forms of communications or technologies.

Participants are usually fitted with head mounted displays that send slightly different images to each eye. The disparity in images creates the illusion of depth. 
Head mounted displays (HMDs) are also fitted with head tracking devices that allow the field of vision to change as the participant moves (Riva, 2003). Separate headphones for each ear create stereophonic sound which can help give the illusion of movement, distance, location or speed. Participants can also be fitted with devices such as data gloves that track bodily movements (Bullinger, Roessler, \& MuellerSpahn, 1998). Tracking devices enable participants to move and interact with objects. Some researchers have also introduced tactile (Carlin, Hoffman, \& Weghorst, 1997) and olfactory (Gerardi, Rothbaurn, Ressler, Heekin, \& Rizzo, 2008) stimulation to mimic happenings in the virtual world. Virtual Environments (VEs) can be generated by most desktop or high end laptop computers (Glantz, Rizzo, \& Graap, 2003).

Although psychological research in VR began in the 1980s, use outside the laboratory has only recently begun to increase, in large part due to the technology becoming more affordable. It is now possible to set up a simple VR system for about $\$ 6000$ (Riva, 2003). In Europe, there is a large scale community project set up solely for the development of different VR modules that can be used in clinical psychology (the VEPSY project, Riva et al., 2003).

\subsection{VR in Psychotherapy}

Reviews of VR have been conducted (e.g., Powers \& Emmelkamp, 2008), however these reviews have included those studies assessing VR as a standalone treatment or to reduce therapist contact. The present review focused only on those studies with VR as an adjunct to therapy. Twenty-four studies were identified and are summarized in Table 3. Seven studies contained sufficient information to calculate effect sizes. 


\subsection{VR in Interventions}

4.3.1. VR for exposure therapy. The majority of research in this field has investigated the use of VR in exposure therapy for anxiety disorders. Current treatment for phobias and stress related disorders typically involve the patient experiencing repeated exposure to feared stimulus, whilst practising relaxation and cognitive techniques (Garshnek, 2002). Stimuli are presented in graded exposure using a fear hierarchy. It has been argued that exposure to feared stimulus activates the underlying fear structure of the disorder, and allows for modification of the pathological elements of the structure (Foa \& Kozak, 1986; van Minnen \& Foa, 2006)

Exposure can be real or imagined. A scenario from the fear hierarchy can be imagined whilst practising relaxation, i.e., “imaginal” exposure (Riva, Molinari, \& Vincelli, 2001). Alternatively, the patient can be exposed to real feared stimulus; known as “in vivo” exposure (Riva, Molinari et al., 2001). Although in vivo is generally regarded as more effective than imaginal exposure, the advantage of the latter is that it can be more affordable, and practical for patients not ready or able to face their feared stimulus (Garcia-Palacios, Hoffman, Carlin, Furness, \& Botella, 2002).

VR has the potential to provide a bridge between imaginal and in vivo exposure. Patients can become immersed in virtual worlds and experience real physiological and psychological responses, while remaining in the safety of a controlled environment (Glantz et al., 2003). VR can also be a more affordable option than in vivo exposure, particularly for treating phobias such as fear of flying. Of the studies reviewed, strong effect sizes were found for exposure therapy with VR.

4.3.2. VR and phobias. Two studies examined the use of VR in the treatment of fear of flying (Wallach \& Bar-Zvi, 2007; Wiederhold, Jang, Kim, \& Wiederhold, 
2002). VR technology has been used to simulate elements of flights, such as take-off, landing, and turbulence. In one study VR exposure was administered to 36 participants with a fear of flying (Wiederhold et al., 2002). Phobic participants differed significantly from the 22 non-phobic participants on physiological and subjective fear arousal to airplanes. Thirty-three of the phobic participants responded to VR-Therapy (VRT), with physiological and psychological measures of distress declining towards those of the non-phobic participants.

It should be noted that analyses only compared between phobic and nonphobic groups, not between baseline and post treatment scores (Wiederhold et al., 2002). It is unclear how substantial these gains were, for how long they were maintained, or how results compare to traditional in vivo or imaginal treatments. However, Wallach and Bar-Zvi (2007) analysed baseline and post-treatment scores. VRT significantly improved participants' fear of flying, with a strong treatment effect size found. However, this study also lacked a control or comparison group, and did not include long term follow up data.

VR has been used in the treatment of fear of driving. Utilizing a multiple baseline approach Wald (2004) treated five participants with weekly VR sessions. VR scenarios included driving a car along a rural route and urban industrial route. Three of the five participants showed improvements on subjective levels of distress. However, these improvements declined at the one and three month follow ups, and the treatment did not result in increased in driving behaviors. One participant also showed significantly worse global phobia at post treatment.

Three studies examined VRT in the treatment of acrophobia, or fear of heights. Although two of these studies used single case designs (Jang et al., 2002; Kahan, 2000), Rothbaum and colleagues (1995) compared VR to a waitlist control in 
a randomised controlled trial. All three studies demonstrated positive effects related to VR exposure therapy, with strong effect sizes found. However as no study examined a comparable treatment group it is unclear whether VRT provided any additional benefits to that of imaginal or in vivo exposure therapy.

Agoraphobia is the extreme and irrational fear of being in a situation from which escape might be difficult or embarrassing (American Psychiatric Association, 2000). Three studies examined the use of VR in the treatment of agoraphobia (Jang, Ku, Shin, Choi, \& Kim, 2000; North, North, \& Coble, 1995; Penate, Pitti, Bethencourt, de la Fuente, \& Gracia, 2008). North et al. (1995) found VRT to be an effective method of treatment when compared to a control group, with a strong effect size found. Yet Jang et al. (2000) found difficulties in immersing participants in the VEs due to small field of vision in the head mounted display. Lack of immersion resulted in poor treatment effects and early termination of the study (Jang et al., 2000).

The third study compared traditional CBT to combined CBT with VR exposure (Penate et al., 2008). VEs included a highway, cableway, and underground car park. Both treatment groups responded well to therapy, and significant improvements were shown on all scales including anxiety, depression and agoraphobic cognitions. There were no significant differences between the groups at post treatment or three month follow up; indicating VR did not confer any additional benefits to traditional exposure methods. However, at follow up a greater number of participants from the VRT than CBT group had discontinued use of anti-anxiety medications, which may suggest a difference between treatments in the maintenance of gains. 
Social phobia involves the extreme and persistent fear of social or performance situations in which embarrassment may occur (American Psychiatric Association, 2000). It is a complex phobia to treat with VR, as it involves the creation of virtual humans or “avatars” (Gaggioli, Mantovani, Castelnuovo, Wiederhold, \& Riva, 2003; Glantz, Durlach, Barnett, \& Aviles, 1996). For such avatars to be effective they must produce the same emotions and reactions in their human counterparts as would be expected from a normal interaction (Glantz et al., 2003). This technology is still being developed, with a lack of realistic programs available. VR exposure has been effective for treating an element of social phobia; the fear of public speaking (Anderson, Rothbaum, \& Hodges, 2003).

In two separate case studies VR was used to expose patients to public speaking in front of a small audience (Anderson et al., 2003). The virtual audience consisted of five people seated around a conference table, with the therapist controlling the audience reactions so that they appear interested, bored, neutral or applauding. Following treatment, both participants improved on self reported measures of public speaking anxiety. However, the study lacked a control group or multiple baseline design, and no statistical analysis of data was reported. However, this study demonstrates the potential for virtual humans to be used in the treatment of disorders involving social interaction. Research in this field is still in early days, but shows considerable promise particularly through behavioral role playing (Anderson, Rothbaum, \& Hodges, 2001).

4.3.3. VR and PTSD. VR has also been used in the treatment of PTSD, with medium treatment effect sizes found throughout the literature. Unlike phobias, in vivo exposure therapy is often difficult when treating PTSD. Repeated exposure to trauma related scenes presents obvious practical and ethical issues. As such, imaginal 
exposure is often used (Difede, Hoffman, \& Jaysinghe, 2002). While this method is the current standard in CBT, it has been noted that patient failure to engage emotionally in exposure can lead to poor treatment outcome (Jaycox, Foa, \& Morral, 1998). Emotional engagement in treatment can be difficult by means of imaginal exposure. Indeed, one randomized control trial of PTSD treatments found 75\% of patients assigned to imaginal exposure still met diagnostic criteria at six month follow up (Bryant et al., 2008). However VR provides a promising alternative to increase emotional engagement and provide more realistic exposure therapy.

Five studies addressed the efficacy of using VR for exposure therapy for PTSD (Gerardi et al., 2008; Reger \& Gahm, 2008; Rothbaum, Hodges, Ready, Graap, \& Alarcon, 2001; Rothbaum, Ruef, Litz, Han, \& Hodges, 2003; Wood et al., 2009). While four of these studies were single case designs, the study conducted by Rothbaum et al. (2001) involved 16 Vietnam veterans. Participants completed twice weekly 90 minute VRT sessions, over five to seven weeks. VEs included jungle clearings, mine explosions, and helicopters. A subwoofer was also placed underneath the patient seat that allowed helicopter vibrations to be felt. During VR exposure the therapist was able to communicate with the patient via a microphone.

The overall mean score on the Clinician Administered PTSD Scale (CAPS) fell from the clinically severe range to the clinically moderate range following treatment (Rothbaum et al., 2001). Significant declines were reported in all three symptom clusters of avoidance, re-experiencing, and arousal. Improvements were observed on the Impact of Event Scale immediately following treatment and at three month follow up, however some gains were lost at six month follow up. Lack of a control or comparison group hinders analysis of individual treatment effects related to addition of the VR exposure element. Dropout rates were high with only nine 
participants remaining at the end of treatment. Although dropout is usually high among this population, the observed rate was somewhat higher than the average $14 \%$ reported in a meta-analysis of PTSD psychology treatments (Van Etten \& Taylor, 1998).

Despite these limitations, the Rothbaum et al. (2001) findings are supported by other research in the area. A case study reported by Wood et al. (2009) found VR exposure therapy to be effective in the treatment of PTSD for a female returned from three tours of duty in Iraq. VEs involved a virtual Baghdad, convoy and village. The participant was able to walk through the environment, drive a Humvee and fire a gun. Following treatment, the participant's symptom severity declined from diagnostic to non-diagnostic levels and gains were maintained at three month follow up. Virtual Iraq exposure was also used in case reports by Reger and Gahm (2008) and Gerardi et al. (2008). VR exposure in the Gerardi et al. (2008) study went so far as to include olfactory stimuli, with scents such as burning rubber, diesel fuel and weapons. Both of studies found positive effects of VR exposure (Gerardi et al., 2008; Reger \& Gahm, 2008) as did a third case report conducted by Rothbaum et al. (2003).

VR exposure may be an important tool in the treatment of PTSD. It allows the clinician to manipulate the exposure environment beyond what would be possible in the real world, providing new opportunities for treatment (Difede et al., 2002). VR technology may be able to enhance current imaginal therapy practices by providing more realistic exposures and facilitating greater emotional engagement in the treatment.

4.3.4. VR and eating disorders. Four studies have examined the use of VR in the treatment of eating disorders. Two randomized controlled studies conducted by Riva et al. (2001, 2002) compared CBT to combined CBT-VR in the treatment of 
Binge Eating Disorder (BED) and obesity. The VR component of the CBT-VR included cognitive strategies such as countering, label shifting and temptation exposure. Subjects were exposed to three dimensional bodies in an effort to modify the bodily experience of the participant. The three dimensional bodies were used during guided imagery, whereby participants could make alterations to the presentation of the bodies. VR components were combined with a low calorie diet and physical training. Participants in the CBT group received the same low calorie diet and physical training with added psychonutritional group therapy.

Results of the Riva et al. (2001) study found that while both treatments benefited participants, the combined CBT-VR treatment was more effective than the CBT alone treatment in reducing body dissatisfaction and anxiety levels among obese participants. Furthermore Riva et al. (2002) found that BED participants in the combined CBT-VR group were less concerned about social judgment at the end of the treatment period, and also showed signs of reduced overeating. The combined CBTVR therapy was again found to be more effective than CBT for improving self efficacy, body satisfaction and lowering anxiety levels.

The studies conducted by Riva et al. (2001; 2002) demonstrate how VR can be a valuable technological adjunct, provided it is based on sound psychological principles and applications. The incorporation of cognitive and behavioural strategies into three dimensional VEs may help patients better understand the treatment principles, and allow them to practise applying them in safe environments. It should be noted however that in the two randomised control trials (Riva, Bacchetta et al., 2001; Riva et al., 2002) individual VR training was compared against group psychonutritional training. It is therefore possible that the additional benefits 
associated with the CBT-VR program may in fact be due to the VR participants receiving more individualised attention than those in the group therapy program.

\subsection{VR for Assessment}

To date, two studies have examined VR as a possible diagnostic tool, both in assessing severity of schizophrenic symptoms.

4.4.1. VR medication management. The first study, conducted by Kurtz et al. (2007), assessed medication management skills of 25 participants with schizophrenia and 18 healthy control participants. Participants became immersed in a virtual apartment where they were allowed to explore and complete tasks. Participants were shown a virtual medication regime, which they had to adhere to during their time in the VE. Patients with schizophrenia made more quantitative (taking too many or too little tablets) and qualitative (taking tablets at the wrong time or forgetting) medication mistakes than the healthy controls. In addition, the schizophrenic patients made less use of external prompts such interactive clocks and reminders. This study demonstrates how VR may be useful for clinicians in assessing a patient's capacity to adhere to a medication regime.

4.4.2. VR and working memory. Sorkin et al. (2006) also examined the use of VR in the assessment of schizophrenic functionality. Thirty-nine schizophrenic patients and 21 healthy controls completed a VR computer navigation game that relied on sensory integration in working memory. Discriminant analysis was able to separate $85 \%$ (33 of 39) of the schizophrenic patients, with the two groups of participants differing significantly on their performance in the virtual maze. VR games such as these may become a valuable tool for clinicians in assessing patient severity, and working memory capacity. Patients with schizophrenia may even enjoy 
and appreciate this method of assessment more than traditional methods (Freeman, 2008).

\subsection{Current Research, Limitations and Future Directions}

Current research in the field of VR has focused largely on the treatment of anxiety related disorders such as specific phobias and PTSD. However, VR is also beginning to cross into other treatment fields such as eating disorders and schizophrenia. Results have been promising, with many studies suggesting benefits associated with the use of the new technology. However, there is a lack of studies utilizing randomised controlled trials or active treatment comparison groups.

Furthermore, as with any new treatment component, it is important that guidelines be developed to ensure best practice for all clinicians. VR technology enables the construction of environments and situations that would otherwise not be accessible in the real world. Clinicians must therefore be careful that they define the upper limits of anxiety provoking stimulus that is appropriate for use with each individual client so as not to cause any unnecessary distress or discomfort to clients, nor intensify anxiety or fears (Garshnek, 2002). Although some researchers have advocated the use of VR in the desensitization of painful and disturbing memories, others have called for caution with concerns that false memories could be implanted (Glantz et al., 1996).

There are also still technological issues associated with VR. At present there is a lack of standardised VR software that is ready to use for clinicians (Riva, 2003). This software is often difficult to tailor to the needs of each individual, with technical support and maintenance being costly (Riva, 2009). One possible solution to this problem is an internet based VR platform (http://neurovr.org) that allows non experts to modify VEs easily with a database of objects and the capability to add scanned 
objects (Riva, 2009). Tools such as these may make VR a more user friendly and appealing option to many therapists.

Lastly, it has also been reported that some people may experience "simulator sickness” following exposure to VR. Symptoms associated with simulator sickness have included eyestrain, blurred vision, fatigue, disorientation, balance disturbances and nausea (Riva, 2003). Research may therefore need to clarify characteristics of those at risk of simulator sickness, and develop a screening process.

Despite limitations, VR has great potential to enhance current psychotherapy practises. One mechanism behind the success of VR is the sense of immersion in VEs, which better facilitates the transfer of therapeutic skills to real world environments than other traditional psychotherapeutic methods. This transfer process may result in more positive treatment outcomes, particularly in the maintenance of gains following treatment.

VR also allows for exposures that may otherwise be impossible or difficult to arrange (Rothbaum et al., 2001). It allows for greater control over the exposure environment, making graded exposure much easier. Furthermore, VR exposure therapy may appear to be less threatening than in vivo exposures. Indeed, one study has found approximately $89 \%$ of people would prefer VR exposures to in vivo exposures, suggesting VR may be a valuable tool in increasing help seeking behavior (Garcia-Palacios, Hoffman, See, Tsai, \& Botella, 2001).

VR treatment may also be able to be combined with biofeedback methods, a possibility that has not yet been explored. Researchers have already noted that physiological monitoring may aid greatly in verification of emotional processing (Wiederhold \& Wiederhold, 2000). However active feedback to the patient may also aid in their control of physiological states whilst immersed in VEs. 
Although not empirically tested yet, VR may prove useful in training new psychologists (Beutler \& Harwood, 2004). With the advancement of avatar technology, trainees may be able to hone their skills on virtual clients in a more realistic version of current role playing techniques. There are many ways in which VR may be able to enhance current psychotherapy techniques, many of which have yet to be fully explored. However, as research stands to date, there are already many VR options readily available to clinicians, many of which have shown treatment efficacy across a variety of studies. VR is a technological adjunct that is likely be increasingly adopted by practicing clinicians.

\section{General Conclusions}

The purpose of the present paper was to identify and review technologies to enhance current psychotherapy practices. Four types of technological adjuncts were identified; mobile phones, PDAs, biofeedback, and VR.

Research has shown mobile phones and PDAs to be effective for electronic data collection and intervention techniques. Although these two devices provide similar services, mobile phones may be a more practical and feasible choice for clinicians due to increased functionality and high penetration rates. Mobiles phones also have the added advantage of being personally and socially linked with the client.

Although there is currently limited research in this field, the opportunities for mobile phones to be incorporated in psychotherapy are vast. Programmable Smartphones would allow delivery of specialized therapeutic content and activities, which may be accessed whenever and wherever the client chooses. Such programs may increase client engagement during and between therapy sessions, and increase adherence with homework tasks. Applications may also be able to remind clients to take required medications throughout the day (e.g., Arsand, Tatara, Ostengen, \& 
Hartvigsen, 2010; Hoffman et al., 2010). Such applications would bridge between innovations in behavioral and pharmaco-therapies. Indeed, mobile phones are likely to become an increasingly important adjunct at the disposal of clinical psychologists and researchers.

Biofeedback may be useful in the delivery of various treatment techniques that aim to relax, and reduce anxiety and stress. However, there is a current lack of research assessing biofeedback as an adjunct to psychotherapy practices, rather than as a separate treatment alternative. The popularity of biofeedback may increase in the future given the expanding view of effective treatment options such as mindfulness therapy. Biofeedback may be particularly useful for clients to understand and identify the symptoms of various mental health conditions (Winfield, 1983). Furthermore, with the rise of affordable and portable devices, biofeedback is likely to increase in usage throughout clinical psychology.

Of the adjuncts reviewed in this paper, VR has been the most documented and researched technology. It has been used in the treatment of anxiety related disorders, schizophrenia, and eating disorders. Yet this technology is not a treatment in itself. As with imaginal or in vivo exposures, VR is the tool for therapy; the techniques must still be taught and guided by the therapist. It is important for therapists and researchers to view VR as a technological adjunct to current treatment, not as a new form of treatment.

In implementing technologies into psychotherapy, compliance may be enhanced through the use of technologies that are structured and guided (Celio, Winzelberg, Dev, \& Taylor, 2002), contain task reminders (Celio et al., 2002), tailored material (Bull et al., 2005), user friendly designs (Rothbaum, 2004), and interactive applications (Bull et al., 2005). Some research has also suggested that the 
efficacy of psychological technologies may be moderated by age, with best results observed for middle aged rather than older or younger clients (Barak et al., 2008). However, it should be noted that the majority of this research has been conducted on compliance to internet based or electronic self help programs. There is a current lack of research investigating client compliance to technological adjuncts in traditional face to face therapy. Interestingly, researchers have also speculated that client compliance may be greater for mobile phone adjuncts than for other technological adjuncts (Preziosa et al., 2009). Mobile phones have been found to be popular even among people who may not normally use computers or other technologies (Fortunati, 2002).

Where effect sizes could be calculated, moderate to strong treatment effects were observed for technological adjuncts reviewed in this paper. For clients, this represented substantial reductions in abnormal symptoms and increased treatment gains. Considering the substantial financial impact of conditions such as depression and anxiety disorders (Fostick, Silberman, Beckman, Spivak, \& Amital, 2010; Koerner et al., 2004), technological adjuncts may not only provide improved treatments for clients, but a reduction in the financial burdens associated with mental health conditions. Future research should examine the cost utility of the inclusion of such devices into psychotherapeutic care.

This review also identified limitations of technologies currently used. The psychological community would benefit from standardized procedures and softwares for devices, as well as ethical guidelines for their use. Appropriate data management systems are also a necessity. Therapists must also be aware of any possible side effects, such as those associated with biofeedback and VR. Importantly, technologies should not be included ad hoc, or without appropriate consideration or planning. That 
is, technological adjuncts should fit with the treatment protocol and be acceptable to both therapist and client. Important issues may be the accessibility of these devices and also training of therapists in their use. Therapist training in the use of technology has been identified as an important issue for best practice delivery of etherapy (Abbott, Klein, \& Ciechomski, 2008), and many codes of ethics now contain guidelines for their use (e.g., American Psychological Association, 2010). However, therapist training in the use of technological adjuncts in traditional face to face therapy has not been addressed to date.

This field is also lacking in methodological rigour. Very few of the studies reviewed in this paper contained a control or comparison treatment group, even fewer used randomization of conditions. Furthermore, the reporting of appropriate data is also lacking. This deficit was demonstrated in the comparatively few effect sizes that were able to be calculated. These are issues needing to be addressed in future research.

There has also been very little research examining the suitability of technological adjuncts to different types of therapy. Casper (2004) has theorized that not all psychotherapy approaches may lend themselves equally well to technological applications. Practitioners of a cognitive behavioral background have been found to express higher levels of endorsement toward technologically based therapeutic tools, than practitioners of other theoretical backgrounds (Mora, Nevid, \& Chaplin, 2008). A recent meta-analysis has also found CBT to be more effective than other therapeutic approaches, when applied online (Barak et al., 2008). Future research should address whether particular therapies are more amenable to making use of adjunctive technologies than others. 
Psychotherapy, irrespective of the theoretical approach, is not perfect. Many therapists experience ongoing problems with client dropout, homework compliance and residual symptoms following completion of treatment. Research has demonstrated many methods of incorporating technology to enhance existing psychotherapy practices. Future research should focus on more rigorously controlled studies, expanding technology into new areas of clinical practice, and in combining various forms of technology, such as biofeedback with VR. Most importantly, although electronic therapies have their place in psychology, there is more to the use of technology than simply broadening the reach of psychological interventions (Casey \& Halford, 2010). Many clients will still want face to face therapy, and the use of technological adjuncts may be able to enhance this experience. It is important that researchers and clinicians begin to become aware of and build on these possibilities. 


\section{References}

Abbott, J. A. M., Klein, B., \& Ciechomski, L. (2008). Best practices in online therapy. Journal of Technology in Human Services, 26, 360-375.

Addis, M. E., \& Jacobson, N. S. (2000). A closer look at the treatment rationale and homework compliance in cognitive-behavioral therapy for depression. Cognitive Therapy and Research, 24(3), 313-326.

Ager, A. (1991). The role of microcomputers in clinical psychology Microcomputers and clinical psychology: Issues, applications and future developments (pp. 119). Oxford, England: John Wiley \& Sons; England.

American Psychiatric Association. (2000). Diagnostic and Statistical Manual of Mental Disorders: DSM-IV-TR (4th ed.). Washington, DC: American Psychiatric Publishing.

American Psychological Association. (2010). Ethical principles of psychologists and code of conduct. Retrieved August 23, 2010, from http://www.apa.org/ethics/code/index.aspx

Anderson, P., Rothbaum, B. O., \& Hodges, L. (2001). Virtual reality: Using the virtual world to improve quality of life in the real world. Bulletin of the Menninger Clinic, 65(1), 78.

Anderson, P., Rothbaum, R. O., \& Hodges, L. F. (2003). Virtual reality exposure in the treatment of social anxiety. Cognitive and Behavioral Practice, 10(3), 240247.

Arsand, E., Tatara, N., Ostengen, G., \& Hartvigsen, G. (2010). Mobile phone-based self-management tools for type 2 diabetes: the few touch application. Journal of Diabetes Science and Technology, 4(2), 328-336. 
Attwood, T. (2004). Cognitive behaviour therapy for children and adults with Asperger's syndrome. Behaviour Change, 21(3), 147-161.

Axelson, D. A., Bertocci, M. A., Lewin, D. S., Trubnick, L. S., Birmaher, B., Williamson, D. E., et al. (2003). Measuring mood and complex behavior in natural environments: Use of ecological momentary assessment in pediatric affective disorders. Journal of Child and Adolescent Psychopharmacology, 13(3), 253-266.

Banjanovic, A. (2010). Special Report: Towards Universal Global Mobile Phone Coverage. Retrieved 27/04/10, 2010, from www.euromonitor.com

Barak, A., Hen, L., Boniel-Nissim, M., \& Shapira, N. (2008). A comprehensive review and a meta-analysis of the effectiveness of internet-based psychotherapeutic interventions. Journal of Technology in Human Services, 109-160.

Bauer, S., Percevic, R., Okon, E., Meermann, R., \& Kordy, H. (2003). Use of text messaging in the aftercare of patients with bulimia nervosa. European Eating Disorders Review, 11(3), 279-290.

Beutler, L. E., \& Harwood, T. M. (2004). Virtual reality in psychotherapy training. Journal of Clinical Psychology, 60(3), 317-330.

Biondi, M., \& Portuesi, G. (1994). Tension-type headache - Psychosomatic clinicalassessment and treatment. Psychotherapy and Psychosomatics, 61(1-2), 41-64.

Boschen, M. J., \& Casey, L. M. (2008). The Use of Mobile Telephones as Adjuncts to Cognitive Behavioral Psychotherapy. Professional Psychology-Research and Practice, 39(5), 546-552. 
Boschen, M. J., Neumann, D. L., \& Waters, A. M. (2009). Relapse of successfully treated anxiety and fear: Theoretical issues and recommendations for clinical practice. Australian and New Zealand Journal of Psychiatry, 43(2), 89-100.

Botella, C., Banos, R. M., Perpina, C., Villa, H., Alcaniz, M., \& Rey, A. (1998). Virtual reality treatment of claustrophobia: a case report. Behaviour Research and Therapy, 36(2), 239-246.

Brezinka, V. (2008). Treasure Hunt - a serious game to support psychotherapeutic treatment of children. Ehealth Beyond the Horizon - Get It There, 136, 71-76.

Bryant, R. A., Moulds, M. L., Guthrie, R. M., Dang, S. T., Mastrodomenico, J., Nixon, R. D. V., et al. (2008). A randomized controlled trial of exposure therapy and cognitive restructuring for posttraumatic stress disorder. Journal of Consulting and Clinical Psychology, 76(4), 695-703.

Bull, S. S., Gaglio, B., McKay, H. G., \& Glasgow, R. E. (2005). Harnessing the potential of the internet to promote chronic illness self-management: diabetes as an example of how well we are doing. Chronic Illn, 1(2), 143-155.

Bullinger, A. H., Roessler, A., \& Mueller-Spahn, F. (1998). From toy to tool: the development of immersive virtual reality environments for psychotherapy of specific phobias. Stud Health Technol Inform, 58, 103-111.

Burns, D. D., \& Nolenhoeksema, S. (1991). Coping styles, homework compliance, and the effectiveness of cognitive behavioral-therapy. Journal of Consulting and Clinical Psychology, 59(2), 305-311.

Carlbring, P., \& Andersson, G. (2006). Internet and psychological treatment. How well can they be combined? Computers in Human Behavior, 22(3), 545-553. 
Carlin, A. S., Hoffman, H. G., \& Weghorst, S. (1997). Virtual reality and tactile augmentation in the treatment of spider phobia: A case report. Behaviour Research and Therapy, 35(2), 153-158.

Casey, L. M., \& Halford, W. K. (2010). Couples and the Silicon Chip: Applying Technology to Couple Relationship Services. In K. Hahlweg, M. Grawe \& D. Baucom (Eds.), Enhancing Couples: The Shape of Couple Therapy to Come (pp. 216 - 230). Hogrefe: Gottingen.

Caspar, F. (2004). Technological developments and applications in clinical psychology and psychotherapy: Introduction. Journal of Clinical Psychology, 60(3), 221-238.

Celio, A. A., Winzelberg, A. J., Dev, P., \& Taylor, C. B. (2002). Improving compliance in on-line, structured self-help programs: evaluation of an eating disorder prevention program. J Psychiatr Pract, 8(1), 14-20.

Chandler, C., Bodenhamer-Davis, E., Holden, J. M., Evenson, T., \& Bratton, S. (2001). Enhancing Personal Wellness in Counselor Trainees Using Biofeedback: An Exploratory Study. Applied Psychophysiology and Biofeedback, 26(1), 1.

Chiesa, A., \& Serretti, A. (2010). A systematic review of neurobiological and clinical features of mindfulness meditations. Psychological Medicine, 40(8), 12391252.

Coben, R., Linden, M., \& Myers, T. (2010). Neurofeedback for Autistic Spectrum Disorder: A Review of the Literature. Applied Psychophysiology and Biofeedback, 35(1), 83.

Collins, R. L., Kashdan, T. B., \& Gollnisch, G. (2003). The feasibility of using cellular phones to collect ecological momentary assessment data: Application 
to alcohol consumption. Experimental and Clinical Psychopharmacology, 11(1), 73-78.

Computer Industry Almanac. (2003). Smartphones are Impacting PDA Sales [Press Release]. Retrieved June 7, 2010, from http://www.c-i-a.com/pr0603.htm Computer Industry Almanac. (2006). Smartphone to Outsell PDAs by 5:1 in 2006 [Press Release]. Retrieved June 7, 2010, from http://www.c-ia.com/pr0306.htm

Coyle, D., Doherty, G., Matthews, M., \& Sharry, J. (2007). Computers in talk-based mental health interventions. Interacting with Computers, 19(4), 545-562.

Coyle, D., Matthews, M., Sharry, J., Nisbet, A., \& Doherty, G. (2005). Personal Investigator: A therapeutic 3D game for adolescent psychotherapy. Interactive Technology and Smart Education, 2, 73-88.

Detweiler-Bedell, J. B., \& Whisman, M. A. (2005). A lesson in assigning homework: Therapist, client, and task characteristics in cognitive therapy for depression. Professional Psychology-Research and Practice, 36(2), 219-223.

Difede, J., Hoffman, H., \& Jaysinghe, N. (2002). Innovative use of virtual reality technology in the treatment of PTSD in the aftermath of September 11. Psychiatric Services, 53(9), 1083-1085.

Elton, D. (1993). Combined use of hypnosis and EMG biofeedback in the treatment of stress-induced conditions. Stress Medicine, 9(1), 25-35.

Favelle, G. K. (1994). Therapeutic applications of commercially available computer software. Computers in Human Services|Computers in Human Services, 11(12), 151-158. 
Ferguson, H., Myles, B. S., \& Hagiwara, T. (2005). Using a personal digital assistant to enhance the independence of an adolescent with Asperger syndrome. Education and Training in Developmental Disabilities, 40(1), 60-67.

Flynn, T. M., Taylor, P., \& Pollard, C. A. (1992). Use of mobile phones in the behavioral treatment of driving phobias. Journal of Behavior Therapy and Experimental Psychiatry, 23(4), 299-302.

Foa, E. B., \& Kozak, M. J. (1986). Emotional processing of fear - Exposure to corrective information. Psychological Bulletin, 99(1), 20-35.

Fortunati, L. (2002). The mobile phone: Towards new categories and social relations. Information Communication \& Society, 5(4), 513-528.

Fostick, L., Silberman, A., Beckman, M., Spivak, B., \& Amital, D. (2010). The economic impact of depression: Resistance or severity? European Neuropsychopharmacology, 20(10), 671-675.

Freeman, A. (2008). Studying and Treating Schizophrenia Using Virtual Reality: A New Paradigm. Schizophrenia Bulletin, 34(4), 605.

Freeman, A., \& Rosenfield, B. (2002). Modifying therapeutic homework for patients with personality disorders. Journal of Clinical Psychology, 58(5), 513-524.

Gaggioli, A., Mantovani, F., Castelnuovo, G., Wiederhold, B., \& Riva, G. (2003). Avatars in clinical psychology: A framework for the clinical use of virtual humans. CyberPsychology \& Behavior, 6(2), 117-125.

Garcia-Palacios, A., Hoffman, H., Carlin, A., Furness, T. A., \& Botella, C. (2002). Virtual reality in the treatment of spider phobia: a controlled study. Behaviour Research and Therapy, 40(9), 983-993. 
Garcia-Palacios, A., Hoffman, H. G., See, S. K., Tsai, A., \& Botella, C. (2001).

Redefining therapeutic success with virtual reality exposure therapy. CyberPsychology \& Behavior, 4(3), 341-348.

Garshnek, V. (2002). Touching the future: applications of virtual reality technology to mental health concerns. International Journal of Healthcare Technology and Management, 4(5), 411-420.

Gerardi, M., Rothbaurn, B. O., Ressler, K., Heekin, M., \& Rizzo, A. (2008). Virtual reality exposure therapy using a virtual Iraq: Case report. Journal of Traumatic Stress, 21(2), 209-213.

Glantz, K., Durlach, N. I., Barnett, R. C., \& Aviles, W. A. (1996). Virtual reality (VR) for psychotherapy: From the physical to the social environment. Psychotherapy, 33(3), 464-473.

Glantz, K., Rizzo, A. S., \& Graap, K. (2003). Virtual reality for psychotherapy: Current reality and future possibilities. Psychotherapy, 40(1-2), 55-67.

Gonzalez, V. M., Schmitz, J. M., \& DeLaune, K. A. (2006). The role of homework in cognitive-behavioral therapy for cocaine dependence. Journal of Consulting and Clinical Psychology, 74(3), 633-637.

Goss, S., \& Anthony, K. (2009). Developments in the use of technology in counselling and psychotherapy. British Journal of Guidance \& Counselling, 37(3), 223-230.

Grassi, A., Preziosa, A., Villani, D., \& Riva, G. (2007). A relaxing journey: The use of mobile phones for well-being improvement. Annual Review of CyberTherapy and Telemedicine, 5, 123-131.

Halmi, K. A., Agras, W., Mitchell, J., Wilson, G., Crow, S., Bryson, S. W., et al. (2002). Relapse predictors of patients with bulimia nervosa who achieved 
abstinence through cognitive behavioral therapy. Archives of General Psychiatry, 59(12), 1105-1109.

Hoffman, J. A., Cunningham, J. R., Suleh, A. J., Sundsmo, A., Dekker, D., Vago, F., et al. (2010). Mobile direct observation treatment for tuberculosis patients: a technical feasibility pilot using mobile phones in Nairobi, Kenya. American Journal of Preventive Medicine, 39(1), 78-80.

Jang, D. P., Ku, J. H., Choi, Y. H., Wiederhold, B. K., Nam, S. W., Kim, I. Y., et al. (2002). The development of virtual reality therapy (VRT) system for the treatment of acrophobia and therapeutic case. IEEE Transactions on Information Technology in Biomedicine, 6(3), 213-217.

Jang, D. P., Ku, J. H., Shin, M. B., Choi, Y. H., \& Kim, S. I. (2000). Objective validation of the effectiveness of virtual reality psychotherapy. CyberPsychology \& Behavior, 3(3), 369-374.

Jaycox, L. H., Foa, E. B., \& Morral, A. R. (1998). Influence of emotional engagement and habituation on exposure therapy for PTSD. Journal of Consulting and Clinical Psychology, 66(1), 185-192.

Jupiter Research. (2004). Jupiter Research Reports PDA Penetration Will Only Reach 7\% of the Overall U.S. Population by 2008, Yet Sees Opportunity for Personal Information Management (PIM) Devices [Press Release]. Retrieved June 7, 2010, from http://www.webmediabrands.com/corporate/releases/04.01.06newjupresearch.html

Kahan, M. (2000). Integration of psychodynamic and cognitive-behavioral therapy in a virtual environment. CyberPsychology \& Behavior, 3(2), 179-183.

Kimhy, D., Delespaul, P., Corcoran, C., Ahn, H., Yale, S., \& Malaspina, D. (2006). Computerized experience sampling method (ESMc): Assessing feasibility and 
validity among individuals with schizophrenia. Journal of Psychiatric Research, 40(3), 221-230.

Klein, B., \& Cook, S. (2010). Preferences for e-mental health services amongst an online Australian Sample. e-Journal of Applied Psychology, 6, 28-39.

Kluger, M. P., \& Karras, A. (1983). Strategies for reducing missed initial appointments in a community-mental-health-center. Community Mental Health Journal, 19(2), 137-143.

Koerner, N., Dugas, M. J., Savard, P., Gaudet, A., Turcotte, J., \& Marchand, A. (2004). The economic burden of anxiety disorders in Canada. Canadian Psychology-Psychologie Canadienne, 45(3), 191-201.

Kranzler, H. R., Abu-Hasaballah, K., Tennen, H., Feinn, R., \& Young, K. (2004). Using Daily Interactive Voice Response Technology to Measure Drinking and Related Behaviors in a Pharmacotherapy Study. Alcoholism: Clinical and Experimental Research, 28(7), 1060-1064.

Kurtz, M. M., Baker, E., Pearlson, G. D., \& Astur, R. S. (2007). A Virtual Reality Apartment as a Measure of Medication Management Skills in Patients With Schizophrenia: A Pilot Study. Schizophrenia Bulletin, 33(5), 1162.

Larson, R. W., Richards, M. H., Raffaelli, M., Ham, M., \& Jewell, L. (1990). Ecology of depression in late childhood and early adolescence - A profile of daily states and activities. Journal of Abnormal Psychology, 99(1), 92-102.

Leroi, A. M., Berkelmans, I., Denis, P., Hemond, M., \& Devroede, G. (1995). Anismus as a marker of sexual abuse - consequenses of abuse on anorectal motility. Digestive Diseases and Sciences, 40(7), 1411-1416. 
Leroi, A. M., Duval, V., Roussignol, C., Berkelmans, I., Peninque, P., \& Denis, P. (1996). Biofeedback for anismus in 15 sexually abused women. International Journal of Colorectal Disease, 11(4), 187-190.

Liebert, T., Archer, J., Munson, J., \& York, G. (2006). An exlporatory study of client perceptions of internet counseling and the therapeutic alliance. Journal of Mental Health Counseling, 28(1), 69-83.

Lubar, J. F., Swartwood, M. O., Swartwood, J. N., \& Odonnell, P. H. (1995). Evaluation of the effectiveness of EEG neurofeedback training for ADHD in a clinical setting as measured by changes in TOVA scores, behavioural ratings, and WISC-R performance. Biofeedback and Self-Regulation, 20(1), 83-99.

Matthews, M., Doherty, G., Sharry, J., \& Fitzpatrick, C. (2008). Mobile phone mood charting for adolescents. British Journal of Guidance \& Counselling, 36(2), 113-129.

McLay, R. N., \& Spira, J. L. (2009). Use of a Portable Biofeedback Device to Improve Insomnia in a Combat Zone, a Case Report. Applied Psychophysiology and Biofeedback, 34(4), 319-321.

Mechling, L., Gast, D., \& Seid, N. (2009). Using a Personal Digital Assistant to Increase Independent Task Completion by Students with Autism Spectrum Disorder. Journal of Autism and Developmental Disorders, 39(10), 1420.

Mora, L., Nevid, J., \& Chaplin, W. (2008). Psychologist treatment recommendations for Internet-based therapeutic interventions. Computers in Human Behavior, 24(6), 3052-3062.

Murdoch, J. W., \& Connor-Greene, P. A. (2000). Enhancing therapeutic impact and therapeutic alliance through electronic mail homework assignments. Journal of Psychotherapy Practice and Research, 9(4), 232-237. 
Myles, B. S., Ferguson, H., \& Hagiwara, T. (2007). Using a Personal Digital Assistant to Improve the Recording of Homework Assignments by an Adolescent With Asperger Syndrome. Focus on Autism and Other Developmental Disabilities, 22(2), 96.

North, M. M., North, S. M., \& Coble, J. R. (1995). Effectiveness of virtual environment desensitization in the treatment of agoraphobia. International Journal of Virtual Reality|International Journal of Virtual Reality, 1(2), 2534.

Penate, W., Pitti, C. T., Bethencourt, J. M., de la Fuente, J., \& Gracia, R. (2008). The effects of a treatment based on the use of virtual reality exposure and cognitive-behavioral therapy applied to patients with agoraphobia. International Journal of Clinical and Health Psychology, 8(1), 5-22.

Powers, M. B., \& Emmelkamp, P. M. G. (2008). Virtual reality exposure therapy for anxiety disorders: A meta-analysis. Journal of Anxiety Disorders, 22(3), 561569.

Preziosa, A., Grassi, A., Gaggioli, A., \& Riva, G. (2009). Therapeutic applications of the mobile phone. British Journal of Guidance \& Counselling, 37(3), 313-325.

Rachman, S., Radomsky, A. S., \& Shafran, R. (2008). Safety behaviour: A reconsideration. Behaviour Research and Therapy, 46(2), 163-173.

Raento, M., Oulasvirta, A., \& Eagle, N. (2009). Smartphones An Emerging Tool for Social Scientists. Sociological Methods \& Research, 37(3), 426-454.

Raffone, A., Tagini, A., \& Srinivasan, N. (2010). Mindfulness and the cognitive neuroscience of attention and awareness. Zygon, 45(3), 627-646.

Ratanasiripong, P., Sverduk, K., Hayashino, D., \& Prince, J. (2010). Setting up the next generation biofeedback program for stress and anxiety management for 
college students: A simple and cost-effective approach. College Student Journal, 44(1), 97.

Reger, G. M., \& Gahm, G. A. (2008). Virtual reality exposure therapy for active duty soldiers. Journal of Clinical Psychology, 64(8), 940-946.

Reiner, R. (2008). Integrating a portable biofeedback device into clinical practice for patients with anxiety disorders: Results of a pilot study. Applied Psychophysiology and Biofeedback, 33(1), 55-61.

Riegel, B., Warmoth, J. E., Middaugh, S. J., Kee, W. G., Nicholson, L. C., Melton, M., et al. (1995). Psychogenic cough treated with biofeedback and psychotherapy - A review and case-report. [Note]. American Journal of Physical Medicine \& Rehabilitation, 74(2), 155-158.

Riva, G. (2003). Virtual environments in clinical psychology. Psychotherapy: Theory, Research, Practice, Training, Vol.40(1-2), pp.

Riva, G. (2009). Virtual reality: an experiential tool for clinical psychology. British Journal of Guidance \& Counselling, 37(3), 337-345.

Riva, G., Alcaniz, M., Anolli, L., Bacchetta, M., Banos, R., Buselli, C., et al. (2003). The VEPSY UPDATED project: Clinical rationale and technical approach. CyberPsychology \& Behavior, 6(4), 433-439.

Riva, G., Bacchetta, M., Baruffi, M., Cirillo, G., \& Molinari, E. (2000). Virtual reality environment for body image modification: A multidimensional therapy for the treatment of body image in obesity and related pathologies. CyberPsychology \& Behavior, 3(3), 421-431.

Riva, G., Bacchetta, M., Baruffi, M., \& Molinari, E. (2001). Virtual reality-based multidimensional therapy for the treatment of body image disturbances in obesity: A controlled study. CyberPsychology \& Behavior, 4(4), 511-526. 
Riva, G., Bacchetta, M., Baruffi, M., \& Molinari, E. (2002). Virtual-reality-based multidimensional therapy for the treatment of body image disturbances in binge eating disorders: A preliminary controlled study. IEEE Transactions on Information Technology in Biomedicine, 6(3), 224-234.

Riva, G., Bacchetta, M., Baruffi, M., Rinaldi, S., Vincelli, F., \& Molinari, E. (2000). Virtual reality-based experiential cognitive treatment of obesity and bingeeating disorders. Clinical Psychology \& Psychotherapy, 7(3), 209-219.

Riva, G., Molinari, E., \& Vincelli, F. (2001). Virtual reality as communicative medium between patient and therapist Communications through virtual technologies: Identity, community and technology in the communication age (pp. 87-100). Amsterdam, Netherlands: IOS Press; Netherlands.

Robinson, S., Perkins, S., Bauer, S., Hammond, N., Treasure, J., \& Schmidt, U. (2006). Aftercare intervention through text messaging in the treatment of bulimia nervosa - Feasibility pilot. International Journal of Eating Disorders, 39(8), 633-638.

Rothbaum, B. (2004). Technology and manual-based therapies. Clinical PsychologyScience and Practice, 11(3), 339-341.

Rothbaum, B., Hodges, L. F., Kooper, R., Opdyke, D., Williford, J. S., \& North, M. M. (1995). Effectiveness of computer-generated (Virtual reality) graded exposure in the treatment of acrophobia. The American Journal of Psychiatry, 152(4), 626.

Rothbaum, B., Hodges, L. F., Ready, D., Graap, K., \& Alarcon, R. D. (2001). Virtual reality exposure therapy for Vietnam veterans with posttraumatic stress disorder. The Journal of Clinical Psychiatry, 62(8), 617. 
Rothbaum, B., Ruef, A., Litz, B., Han, H., \& Hodges, L. (2003). Virtual reality exposure therapy of combat-related PTSD: A case study using psychophysiological indicators of outcome. Journal of Cognitive Psychotherapy, 17(2), 163.

Sorkin, A., Weinshall, D., Modai, I., \& Peled, A. (2006). Improving the accuracy of the diagnosis of schizophrenia by means of virtual reality. The American Journal of Psychiatry, 163(3), 512.

Taylor, D. J., Walters, H. M., Vittengl, J. R., Krebaum, S., \& Jarrett, R. B. (2010). Which depressive symptoms remain after response to cognitive therapy of depression and predict relapse and recurrence? Journal of Affective Disorders, 123(1-3), 181-187.

Van Etten, M. L., \& Taylor, S. (1998). Comparative efficacy of treatments for posttraumatic stress disorder: A meta-analysis. [Article]. Clinical Psychology \& Psychotherapy, 5(3), 126-144.

van Minnen, A., \& Foa, E. B. (2006). The effect of imaginal exposure length on outcome of treatment for PTSD. Journal of Traumatic Stress, 19(4), 427-438.

Wald, J. (2004). Efficacy of virtual reality exposure therapy for driving phobia: A multiple baseline across-subjects design. Behavior Therapy, 35(3), 621-635.

Wallach, H. S., \& Bar-Zvi, M. (2007). Virtual-reality-assisted treatment of flight phobia. Israel Journal of Psychiatry and Related Sciences, 44(1), 29-32.

Wiederhold, B. K., Jang, D. P., Kim, S. I., \& Wiederhold, M. D. (2002). Physiological monitoring as an objective tool in virtual reality therapy. CyberPsychology \& Behavior, 5(1), 77-82.

Wiederhold, B. K., \& Wiederhold, M. D. (2000). Lessons learned from 600 virtual reality sessions. CyberPsychology \& Behavior, 3(3), 393-400. 
Winfield, I. (1983). Counselling with biofeedback: A review. British Journal of Guidance \& Counselling, 11(1), 46-51.

Wood, D. M. U., Webb-Murphy, J. P., Center, K. M., McLay, R. M. D. P., Koffman, R. M. U., Johnston, S. M. U., et al. (2009). Combat-Related Post-Traumatic Stress Disorder: A Case Report Using Virtual Reality Graded Exposure Therapy With Physiological Monitoring With a Female Seabee. Military Medicine, 174(11), 1215.

Yon, B. A., Johnson, R. K., Harvey-Berino, J., Gold, B. C., \& Howard, A. B. (2007). Personal Digital Assistants are Comparable to Traditional Diaries for Dietary Self-Monitoring During a Weight Loss Program. Journal of Behavioral Medicine, 30(2), 165.

Zeman, L. L., Johnson, D., Arfken, C., Smith, T., \& Opoku, P. (2006). Lessons learned: Challenges implementing a personal digital assistant (PDA) to assess behavioral health in primary care. Families, Systems, \& Health, 24(3), 286298. 
Table 1

Mobile Phone and PDA use in Psychotherapy

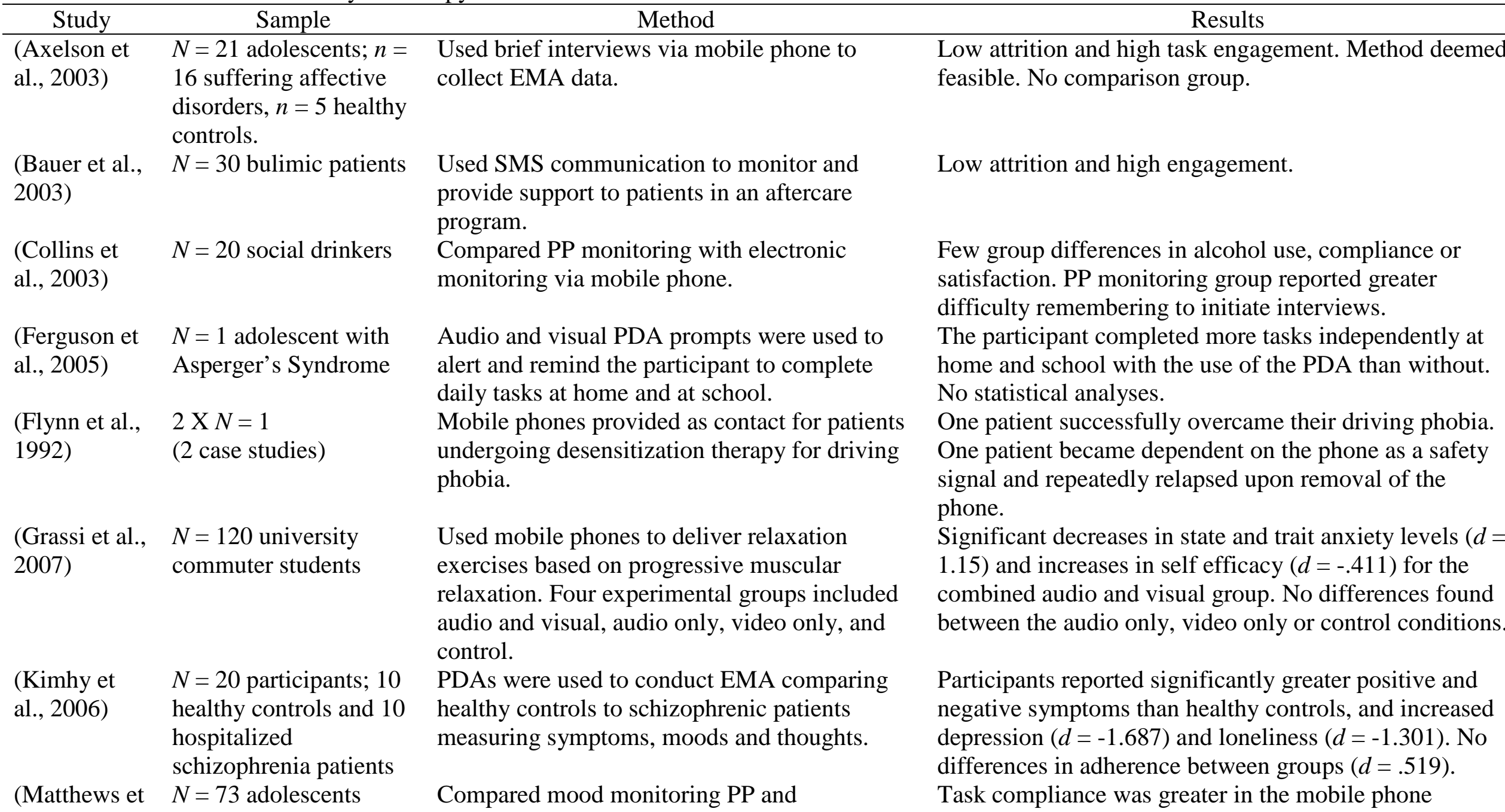


al., 2008)

(Mechling et $N=3$ high adolescents

al., 2009) with a diagnosis of Autism Spectrum

Disorder

(Myles et al., $\quad N=1$ adolescent with

2007) Asperger's Syndrome

(Robinson et $\quad N=21 \mathrm{BN}$ patients

al., 2006) electronically by mobile phone.

A PDA was used to increase student independence for conducting multiple step cooking tasks. The PDA provided prompts to participants throughout the tasks.

A PDA was used to assist the participant in recording and organising school homework tasks.

Used SMS communication to monitor and provide support to patients as an aftercare program. condition, and was also found to be easier to use than the PP methods, although not significantly $(d=.463)$.

Participants became more independent, relying less on peer and teacher prompts. No statistical analyses.

Independent homework recording increased by $29 \%$ from baseline to intervention. No statistical analyses.

Low usage and high attrition. No significant changes pre to post treatment in fear of becoming fat $(d=0)$, or perceptions of body shape $(d=-.111)$, or attractiveness ( $d$ $=-.0285)$. Greater binge episodes reported post intervention than pre intervention $(d=-.200)$ 
Table 2

Biofeedback in Psychotherapy

\begin{tabular}{|c|c|c|c|}
\hline Study & Sample & Method & Results \\
\hline $\begin{array}{l}\text { (Leroi et al., } \\
\text { 1996) }\end{array}$ & $\begin{array}{l}N=15 \text { sexually abused } \\
\text { women suffering from } \\
\text { anismus }\end{array}$ & $\begin{array}{l}\text { Women were offered any combination of } \\
\text { biofeedback, group therapy and individual } \\
\text { therapy. Biofeedback was aimed at reducing } \\
\text { symptoms of anismus. }\end{array}$ & $\begin{array}{l}\text { Eight women fully recovered. Only two recovered by } \\
\text { biofeedback without psychotherapy; indicating the } \\
\text { importance of this component. }\end{array}$ \\
\hline $\begin{array}{l}\text { (McLay \& } \\
\text { Spira, 2009) }\end{array}$ & $\begin{array}{l}N=1 \text { military medical } \\
\text { provider suffering from } \\
\text { anxiety, depression and } \\
\text { insomnia }\end{array}$ & $\begin{array}{l}\text { Combined biofeedback and psychotherapy. } \\
\text { Biofeedback was aimed at reducing insomnia. }\end{array}$ & $\begin{array}{l}\text { Psychotherapy was effective at reducing symptoms of } \\
\text { anxiety and depression, but not insomnia. Biofeedback } \\
\text { helped reduce insomnia. }\end{array}$ \\
\hline $\begin{array}{l}\text { (Ratanasiripo } \\
\text { ng et al., } \\
\text { 2010) }\end{array}$ & $\begin{array}{l}\text { One semester of college } \\
\text { students who sought } \\
\text { help through university } \\
\text { counselling services }\end{array}$ & $\begin{array}{l}\text { Participants completed individual biofeedback } \\
\text { training between counselling sessions. Heart } \\
\text { rate and breathing were of interest. }\end{array}$ & $\begin{array}{l}\text { High compliance with the program, although no statistical } \\
\text { analyses and little detail on measurement of compliance. }\end{array}$ \\
\hline $\begin{array}{l}\text { (Reiner, } \\
\text { 2008) }\end{array}$ & $\begin{array}{l}N=24 \text { participants } \\
\text { currently receiving } \\
\text { CBT for anxiety related } \\
\text { disorders }\end{array}$ & $\begin{array}{l}\text { Participants completed } 20 \text { minutes of } \\
\text { biofeedback training everyday for three weeks. } \\
\text { Heart rate and breathing were of interest. }\end{array}$ & $\begin{array}{l}\text { Declines in state }(d=.660) \text { and trait }(d=.613) \text { anxiety as } \\
\text { well as anger related variables }(d=.591) \text {. Also benefits } \\
\text { for total sleep time }(d=-.499) \text {. }\end{array}$ \\
\hline $\begin{array}{l}\text { (Riegel et al., } \\
\text { 1995) }\end{array}$ & $\begin{array}{l}N=1 \text { patient with } \\
\text { psychogenic cough }\end{array}$ & $\begin{array}{l}\text { Patient completed combined psychotherapy and } \\
\text { EMG biofeedback program. }\end{array}$ & $\begin{array}{l}\text { Self reported cough episodes decreased. Sleep improved } \\
\text { and cough medication reduced. }\end{array}$ \\
\hline
\end{tabular}


Table 3

VR in Psychotherapy

\begin{tabular}{|c|c|}
\hline Study & Sample \\
\hline $\begin{array}{l}\text { (Anderson et } \\
\text { al., 2003) }\end{array}$ & $\begin{array}{l}2 \times N=1 \text { ( } 2 \text { case } \\
\text { studies) fear of public } \\
\text { speaking }\end{array}$ \\
\hline $\begin{array}{l}\text { (Botella et } \\
\text { al., 1998) }\end{array}$ & $\begin{array}{l}N=1 \text { female suffering } \\
\text { claustrophobia }\end{array}$ \\
\hline $\begin{array}{l}\text { (Carlin et al., } \\
\text { 1997) }\end{array}$ & $\begin{array}{l}N=1 \text { female suffering } \\
\text { arachnophobia }\end{array}$ \\
\hline $\begin{array}{l}\text { (Garcia- } \\
\text { Palacios et } \\
\text { al., 2002) }\end{array}$ & $\begin{array}{l}N=23 \text { participants with } \\
\text { arachnophobia }\end{array}$ \\
\hline $\begin{array}{l}\text { (Gerardi et } \\
\text { al., 2008) }\end{array}$ & $\begin{array}{l}N=1 \text { returned soldier } \\
\text { suffering PTSD }\end{array}$ \\
\hline $\begin{array}{l}\text { (Jang et al., } \\
\text { 2000) }\end{array}$ & $\begin{array}{l}N=7 \text { participants } \\
\text { diagnosed with panic } \\
\text { disorder with } \\
\text { agoraphobia }\end{array}$ \\
\hline $\begin{array}{l}\text { (Jang et al., } \\
\text { 2002) }\end{array}$ & $\begin{array}{l}N=1 \text { male diagnosed } \\
\text { with acrophobia }\end{array}$ \\
\hline $\begin{array}{l}\text { (Kahan, } \\
\text { 2000) }\end{array}$ & $\begin{array}{l}N=1 \text { patient with } \\
\text { acrophobia }\end{array}$ \\
\hline
\end{tabular}

(Kurtz et al., $\quad N=43 ; 25$ patients with

One Participant received three day intensive therapy with VR exposure treatment; the other received weekly psychotherapy with VR.

Eight VR graded exposure sessions over three weeks. Scenarios ranged from a small balcony or garden, to a small room with no windows. Twelve sessions of VRT. Exposure involved touching, approaching and watching spiders. Toy spiders were used for tactile stimuli.

Participants randomly allocated to treatment and waitlist control. VR exposure was graded using a fear hierarchy, ranging from looking at a spider to holding a virtual tarantula. A virtual Iraq was constructed, which enabled the participant to relive painful combat memories in exposure therapy.

Participants completed standardized relaxation training prior to VRT. Physiological and subjective measures of distress were recorded throughout each VR session.

VR was used for systematic desensitization.

VE was an open caged elevator that ascended the outside of a steel framed city building.

Patient underwent CBT. VR was later

introduced for exposure to stimulus from a fear hierarchy.

Whilst exploring a VR apartment, participants
Public speaking anxiety decreased from pre to post treatment, although no statistical analyses were performed.

Self report measures of anxiety were reduced, including on the Fear and Avoidance Scale. No statistical analyses.

Participant was improved on measures of anxiety, avoidance, and behaviour toward real spiders. No statistical analyses.

The VR treatment group showed statistical and clinical improvement on all measures including the Fear of Spiders Questionnaire $(d=2.185)$ and the Behavioural Avoidance Test $(d=-1.749)$. No improvements for the waitlist group. Participant reported clinically and statistically significant improvements in PTSD symptoms.

Participants were unable to fully immerse themselves in the VR experience. The VRT was deemed ineffective and cancelled after two sessions.

Measures of physiological and subjective ratings of distress decreased during therapy. No statistical analyses.

Patient flew following treatment, and reported minimal anxiety. No measures of distress nor statistical analyses.

Participants with schizophrenia made significantly more 

healthy controls

(North et al., $\quad N=60$ participants

1995) suffering from agoraphobia without panic disorder

(Penate et al., $\quad N=37$ participants

2008) suffering agoraphobia

(Reger \& $\quad N=1$ returned soldier

Gahm, 2008) suffering PTSD

(Riva, $\quad N=57$ females suffering

Bacchetta,

Baruffi,

Cirillo, \&

Molinari,

2000)

(Riva,

Bacchetta et

al., 2001)

(Riva et al.,

2002)

(Riva,

Bacchetta,

Baruffi,

Rinaldi et al.,

$N=28$ females suffering obesity.

$N=20$ females suffering BED

$N=25$ females suffering suffering obesity were required to take virtual medication at specific times during the session.

Participants were randomly divided into control and experimental conditions. VR scenes included exposure to balconies, bridges and elevators.

Participants were divided into CBT or combined CBT-VR therapy. VR scenarios contained elevators, airports and underground car parks.

Participant undertook combined VRT and CBT. VE consisted of a convoy scene similar to that experienced in Iraq.

Participants undertook combined VRT and

CBT, including methods such as countering, exposure and label shifting, with modification of body image. BED and, $N=18$ females
Participants were randomly assigned to either CBT or combined CBT and VRT groups.

Participants were randomly assigned to CBT or combined CBT and VRT. The control group received psychonutritional therapy.

Participants with eating disorders underwent combined CBT and VRT. VR sessions focused on methods such as countering, exposure and label shifting, and modification of body image. errors in medication dose and timing than healthy controls $(d=1.168)$, indicating that VR may be an appropriate tool for assessing medication management skills.

Subjective distress significantly declined for participants in the experimental condition $(d=2.891)$. No changes were observed in the control condition.

Participants in the CBT and CBT-VR treatments both showed significant declines in agoraphobic behaviours $(d=$ $1.341,1.252$ respectively) and cognitions $(d=1.698,1.887$ respectively). No differences between treatments.

Clinical improvement during treatment, and scored within normal population ranges at post treatment assessment. Gains were maintained at a seven week follow up.

Significantly less problematic eating and social behaviours, and improvements in body satisfaction. No control group and no follow up data.

Combined VRT was more effective than traditional CBT in reducing body dissatisfaction.

VRT was more effective than CBT in improving body satisfaction and reducing overeating and anxiety. Results were maintained in the first month after therapy.

Participants reported improvements in body image

satisfaction and significant reductions in problematic eating behaviours. No control group or follow up. 
2000)

(Rothbaum et $\quad N=20$ college students

al., 1995) suffering acrophobia

(Rothbaum et $N=10$ Vietnam veterans al., 2001) suffering PTSD

(Rothbaum et $\quad N=1$ Vietnam veteran al., 2003) suffering PTSD

(Sorkin et al., $\quad N=60 ; n=39$ patients 2006) $=21$ healthy controls

(Wald, 2004) $\quad N=5$ participants with driving phobia

(Wallach \& $\quad N=4$ participants with Bar-Zvi, fear of flying 2007)

(Wiederhold $\quad N=58 ; n=36$

et al., 2002) participants with fear of flying and $n=22$ control participants

(Wood et al., $\quad N=1$ military female 2009) suffering chronic PTSD
Students randomly assigned to VRT or waitlist control. VEs ranged from footbridges to glass elevators. The therapist provided ongoing feedback.

Participants were exposed to VEs involving Huey helicopters and jungle clearings. A comparison group was not included.

Treatment included VR exposure and CBT.

VEs included a virtual Huey helicopter and a virtual landing zone.

A VR game was developed to assist in the diagnosis of schizophrenia. Game focused on working memory skills.

VR exposure was graded from driving a rural residential route to driving an urban industrial route, during exposure therapy.

Eight sessions of VRT were conducted using anxiety hierarchies. VEs ranged from a stationary plane to take off, landing and flying. VEs ranged from being seated in a stationary airplane to flying in bad weather and landing. Subjective and physiological measures of distress were recorded.
Participant completed CBT-VR. VEs included a virtual Baghdad, convoy and village.
Significant decreases on all measures of anxiety, avoidance, and distress $(d=1.401)$. No differences were found for participants on the waitlist $(d=0.142)$. No follow up data.

Mean treatment score on the clinician administered PTSD scale dropped from the "severe" to "moderate" range ( $d=$ .564). No statistical analyses.

Improvements made on the clinician administered PTSD

scale, and increases in life satisfaction. Gains maintained at six month follow up.

Discriminant analysis separated $85 \%$ of patients with schizophrenia from healthy controls.

Four participants showed significant improvements in phobia ratings. One participant declined significantly. Gains were not maintained at follow ups.

Significant declines in fear of flying as measured by the Attitude Toward Flying Questionnaire $(d=3.126)$. No follow up data obtained.

Thirty-three participants responded to treatment, with physiological and subjective measures of distress returning to those similar to the non-phobic patients.

Patient no longer met diagnostic criteria after 10 sessions. Gains were maintained at three month follow up. 